\title{
Estudos econômicos completos sobre tratamentos da anemia falciforme
}

\author{
Comprehensive economic studies on sickle cell anemia treatments
} Estudios económicos completos sobre tratamientos para la anemia falciforme

\author{
Andréia Insabralde de Queiroz Cardos0 ${ }^{1}$ id https://orcid.org/0000-0002-9431-7484 \\ Marcos Antonio Ferreira Júnior ${ }^{1,2}$ io https://orcid.orgy/0000-0002-9123-232X \\ Carolina Mariano Pompe0 ${ }^{1}$ if https://orcid.org/0000-0003-4454-0140 \\ Caroline Neris Ferreira Sarat' io https://orcid.org/0000-0003-1232-2026 \\ Mayk Penze Cardoso ${ }^{1}$ is https://orcid.org/0000-0003-2130-5738 \\ Maria Lúcia Ivo ${ }^{1}$ io https://orcid.org/0000-0003-2993-4758
}

Como citar:

Cardoso Al, Ferreira Júnior MA, Pompeo CM, Sarat CN, Cardoso MP, Ivo ML, et al. Estudos econômicos completos sobre tratamentos da anemia falciforme. Acta Paul Enferm. 2021;34:AAPE01641.

DOI http://dx.doi.org/10.37689/actaape/2021AR01641

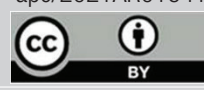

Descritores

Anemia falciforme; Hemoglobina falciforme; Economia da saúde; Custos e análise de custo; Análise custo-benefício

Keywords

Sickle cell disease; Hemoglobin, sickle; Health economics; Costs and cost analysis; Cost-benefit

analysis

Descriptores

Anemia de células falciformes; Hemoglobina falciforme; Economía de la salud; Costos y análisis de costo; Análisis costo-beneficio

Submetido 8 de Julho de 2019

Aceito

29 de Junho de 2020

Autor correspondente Andréia Insabralde de Queiroz Cardoso

E-mail: andreia.cardoso@ufms.br

\section{Resumo}

Objetivo: Analisar os estudos econômicos completos com enfoque nos tratamentos da Anemia Falciforme.

Métodos: Estudo de revisão integrativa de literatura desenvolvido mediante coleta de dados nas bases eletrônicas National Library of Medicine - Medline via PubMed; Elservier's Scopus; Current Index to Nursing and Allied Health Literature; Science Direct e Web of Science com descritores indexados no Medical Subject Headings. Os estudos foram selecionados pelo teste de relevância e analisados de acordo com a classificação das análises econômicas em saúde e o sistema de Classificação da qualidade das evidências e a força das recomendações.

Resultados: Fizeram parte desta revisão 09 artigos, dos quais sete recuperados na base Elservier's Scopus e dois na Medline via PubMed. Todos estudos completos com enfoque nas perspectivas do uso da Hidroxiureia e da transfusão sanguínea no tratamento da Anemia Falciforme.

Conclusão: Não foram identificados estudos realizados no Brasil com este tipo de análise para Anemia Falciforme. Há muito a ser feito mundialmente para avaliação das tecnologias vigentes, reavaliação das utilizadas atualmente e implementação de diagnóstico e tratamento contínuo, com um sistema que garanta uma rede de atenção ativa e eficiente aos pacientes.

\section{Abstract}

Objective: To analyze complete economic studies focusing on sickle cell anemia treatments.

Methods: Integrative literature review developed by collecting data in the electronic databases National Library of Medicine - Medline via PubMed; Elsevier's Scopus; Current Index to Nursing and Allied Health Literature; Science Direct and Web of Science with descriptors indexed in Medical Subject Headings. The studies were selected by the relevance test and analyzed according to the classification of economic analyses in health and the classification system of evidence quality and strength of recommendations.

Results: Nine articles were part of this review, seven of which were retrieved from Elsevier's Scopus and two from Medline via PubMed. All articles reported on complete studies focusing on the perspectives of using hydroxyurea and blood transfusion in the treatment of sickle cell anemia.

Conclusion: No studies were identified that were conducted in Brazil and involved this type of analysis for sickle cell anemia. Much remains to be done worldwide to assess existing technologies, reassess the technologies currently used and implement continuous diagnosis and treatment, by means of a system that guarantees an active and efficient care network for the patients. 


\section{Resumen}

Objetivo: Analizar los estudios económicos completos con enfoque en tratamientos para la anemia falciforme

Métodos: Estudio de revisión integradora de la literatura desarrollado mediante la recolección de datos en las bases electrónicas National Library of Medicine - Medline vía PubMed; Elservier's Scopus; Current Index to Nursing and Allied Health Literature; Science Directy Web of Science con descriptores indexados en Medical Subject Headings. Los estudios fueron seleccionados mediante la prueba de relevancia y analizados de acuerdo con la clasificación de análisis económicos en salud y con el sistema de clasificación de la calidad de las evidencias y la fuerza de las recomendaciones.

Resultados: Nueve artículos formaron parte de esta revisión, de los cuales siete fueron encontrados en la base Elservier's Scopus y dos en Medline vía PubMed. Todos son estudios completos con enfoque en las perspectivas del uso de hidroxiurea y transfusión sanguínea para el tratamiento de anemia falciforme.

Conclusión: No se identificaron estudios realizados en Brasil con este tipo de análisis de anemia falciforme. Hay mucho por hacer a nivel mundial para evaluar las tecnologías vigentes, revaluar las que se utilizan en la actualidad e implementar el diagnóstico y tratamiento continuo, con un sistema que garantice una red de atención activa y eficiente para los pacientes.

\section{Introdução}

A Anemia Falciforme (AF) representa a forma mais grave das Doenças Falciformes a qual envolve condições clínicas decorrentes de alteraçóes genéticas, hereditárias e recessivas com variaçáo estrutural da hemoglobina. Nesta condição, a baixa tensão de oxigênio leva a alteração do eritrócito e a polimerização da hemoglobina $S(\mathrm{Hb} S)$ que passa a ter formato de drepanócitos ou falcizado. ${ }^{(1)}$

$\mathrm{O}$ efeito clínico na alteração da $\mathrm{Hb} \mathrm{S}$ culmina em hemólise ou a vaso-oclusão, com processos inflamatórios e lesóes teciduais nos primeiros anos de vida, que tendem a acentuar e aumentar a gravidade com o passar dos anos, quando lesionam tecidos e órgãos, condição que pode ser fatal. ${ }^{(2)}$

A AF é conhecida como a doença hereditária monogênica mais comum do Brasil, a prevalência foi descrita como maior nas regióes norte e nordeste, com acometimento entre $6 \%$ a $10 \%$ da população, enquanto nas regiốes sul e sudeste ocorreu em apenas $2 \%$ a $3 \%$, respectivamente. ${ }^{(3)}$

A maior taxa de mortalidade nas internaçóes por $\mathrm{AF}$ ocorre em adultos jovens e crianças, em sua maioria por doenças cardíacas, sepse, acidente vascular encefálico (AVE), insuficiência respiratória aguda (IRA) e falência múltipla dos órgãos. ${ }^{(4,5)}$

Existe como opçáo de tratamento o transplante de células-tronco hematopoiéticas alogênicas, com disponibilidade limitada de doadores para menos de $14 \%$ dos pacientes, sendo um tratamento pouco convencional. As principais alternativas são as transfusóes sanguíneas crônicas ou transfusóes de troca como tratamento adjuvante ou a utilização da terapia medicamentosa não curativa com a Hidroxiureia (HU), aprovada mundialmente. ${ }^{(6)}$
Vale ressaltar que o desafio para a melhoria do tratamento dos pacientes com AF consiste no planejamento dos gestores, com base em avaliaçóes econômicas para aprimorar os cuidados. Desta forma, as evidências científicas pautam a tomada de decisão para confiabilidade, recuperaçáo, diagnóstico e tratamento acessíveis as várias populaçôes mundiais. $.5,7)$

Existem recomendaçóes para novas pesquisas de custo-efetividade a partir da perspectiva social, com vistas a embasar melhor os cuidados, diagnósticos, tratamentos, custos diretos e indiretos relacionados a $\mathrm{AF}^{\left({ }^{(8)}\right.}$

Esta revisão integrativa é parte de uma pesquisa para análise do custo-efetividade do tratamento de pacientes com $\mathrm{AF}$ em uso de HU, no qual será desenvolvido um sistema de modelagem computacional para prospecçáo de uma coorte hipotética a fim de analisar a necessidade de investimento, melhorias nos serviços e servir como evidência para a devida tomada de decisóes dos gestores.

Desta forma, esta revisão objetiva analisar os estudos econômicos considerados completos com enfoque nos tratamentos utilizados em pacientes com $\mathrm{AF}$.

\section{Métodos}

Trata de um estudo de revisão integrativa de literatura, o qual consiste em um método rigoroso, com critérios definidos e utilizado pela prática baseada em evidências. Foram seguidos os passos de identificação do problema e elaboração da questão norteadora; busca na literatura com aplicação de critérios de inclusão e exclusão; coleta de dados por meio de instrumento previamente estruturado; análise dos dados e apresentação da revisão. ${ }^{(9,10)}$ 
Para elaboração da questão norteadora foi adotada a estratégia PVO, ${ }^{(11)}$ na qual a letra $\mathrm{P}$ se refere a população/contexto (pacientes com anemia falciforme), a letra $\mathrm{V}$ trata da variável de interesse (estudos econômicos completos) e a letra $\mathrm{O}$, do inglês outcome, remete ao resultado/desfecho (tratamento da anemia falciforme). Assim, foi definida a questão norteadora: "Quais estudos econômicos completos foram realizados com enfoque nos tratamentos de pacientes com Anemia Falciforme?”.

A busca ocorreu no período de janeiro a fevereiro de 2019 por dois revisores de forma independente e uso do Proxy da Universidade Federal do Rio Grande do Norte, para acesso ao Portal de Periódicos CAPES (<http://www-periodicos-capes-gov-br.ez51.periodicos.capes.gov.br/>).

As bases de dados eletrônicas utilizadas foram a National Library of Medicine (Medline via PubMed); Elservier's Scopus (SCOPUS); Current Index to Nursing and Allied Health Literature (Cinahl); Science Direct e Web of Science.

Foram utilizados os descritores controlados indexados no Medical Subject Headings (MeSH): 1\# (Anemia, Sickle Cell); Entry Terms - 2\# (Sickle Cell Disease); 3\# (Costs and Cost Analysis); Entry Terms - 4\# (Cost Analysis); 5\# (Cost Benefit Analysis); Entry Terms - 6\# (Cost
Effectiveness). A busca nas bases foi operacionalizada por dois cruzamentos (A e B) dos descritores com uso dos operadores boleanos AND e OR, a saber: A) \#1 OR \#2 AND \#3 OR \#4 e B) \#1 OR \#2 AND \#5 OR \#6.

Foram incluídos artigos em qualquer idioma, sem limite temporal, completos e relevantes para a proposta da pesquisa. Excluiu-se artigos duplicados, que foram considerados apenas uma vez, revisóes, editoriais, cartas ao editor, resumos, opiniáo de especialistas, resenhas, livros, teses, dissertações, monografias e trabalho de conclusão de curso.

A pré-seleção dos artigos ocorreu com a aplicação do teste de relevância, composto por critérios de inclusão e exclusão, com leitura dos títulos e resumos. Para os artigos selecionados ocorreu a leitura na íntegra e extração dos dados com análise em planilha do Microsoft Excel', conforme a Avaliação Crítica da Evidência: Parte I. ${ }^{(12)}$

As pesquisas foram analisadas com a utilização da Classificação das análises econômicas em saú$\mathrm{de}^{(13)}$ e a qualidade das evidências com o sistema de Classificação da qualidade das evidências e a força das recomendaçóes (GRADE). ${ }^{(14)}$

A coleta de dados seguiu quatro fases, a saber: identificação, seleção, elegibilidade e inclusão, representadas na figura $1 .^{(15)}$

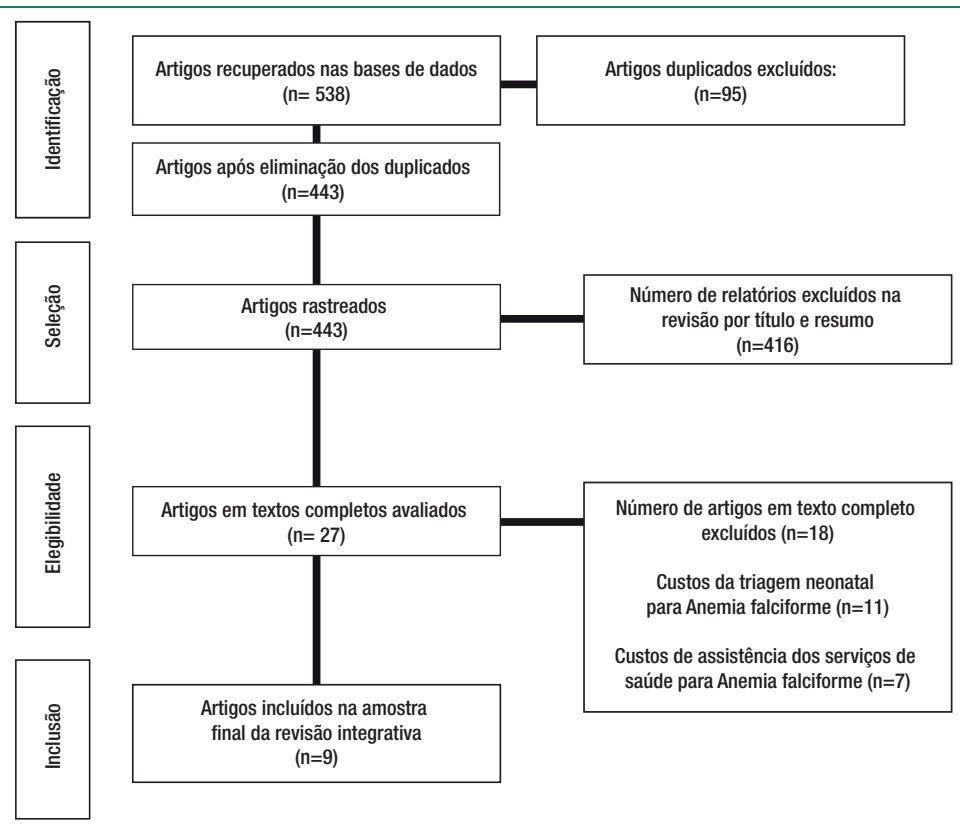

Figura 1. Fases do processo de busca e composição da amostra final de estudos de custo-efetividade com enfoque no tratamento da Anemia Falciforme 


\section{Resultados}

Nas bases analisadas foram recuperados inicialmente 443 artigos, todos rastreados com a leitura de seus títulos e resumos. A seleção baseada no teste de relevância e análise criteriosa resultou em nove artigos para a amostra final, destes sete oriundos da base de dados Scopus e dois da Pubmed.

Os países de origem dos estudos foram os Estados Unidos da América com quatro publicaçóes (44,50\%), o Reino Unido com duas publicações $(22,20 \%)$, seguidos pela Jamaica, Uganda e Porto Rico, com uma publicaçáo cada $(11,10 \%)$.

Dentre os periódicos encontrados dois tiveram destaque, o American Journal Hematology e o Transfusion com duas publicaçóes cada (22,25\%), os demais BMC Health Services Research, Pediatric Blood Cancer, Europen Journal of Haematology, Health
Technology Assessmente Boletín de la Asociación Médica de Puerto Rico apresentaram uma publicação (11,10\%) cada. Os estudos da amostra final foram publicados em idioma inglês, datados inicialmente do ano 2000, com aumento dos estudos a partir de 2010.

Quanto ao tipo de estudo, ${ }^{(13)}$ cinco trataram de custo-benefício $(55,56 \%)$, dois de custo-utilidade $(22,22 \%)$, um de custo-minimização $(11,11 \%)$ e outro de custo-efetividade $(11,11 \%)$. Foram utilizadas simulaçôes de modelagem computacional com modelo de Markov em quatro pesquisas (44,44\%) e uma Simulação de Monte Carlo (11,11\%). Duas pesquisas $(22,22 \%)$ foram consideradas piggyback evaluation por conduzir uma avaliação econômica em paralelo com ensaio clínico randomizado, três $(33,33 \%)$ baseadas em dados de coorte retrospectiva e quatro $(44,45 \%)$ realizaram uma coorte hipotética computacional.

Quadro 1. Caracterização dos estudos de custo-efetividade para o tratamento de pacientes com Anemia Falciforme e respectivas forças de recomendação $(n=9)$

\begin{tabular}{|c|c|c|c|c|}
\hline Autor/ano & $\begin{array}{l}\text { Tipo de análise } \\
\text { econômica }\end{array}$ & $\begin{array}{l}\text { Classificação } \\
\text { GRADE }\end{array}$ & Desenho metodológico & Recomendações e limitações \\
\hline $\begin{array}{l}\text { Moore et al., } \\
2000^{(16)}\end{array}$ & $\begin{array}{l}\text { Completo. } \\
\text { Custo-benefício }\end{array}$ & Alto & $\begin{array}{l}\text { Baseado em ensaio clínico randomizado e controlado em } \\
\text { pediatria ( } n=299) \text {. } \\
\text { Teste de Wilcoxon. } \\
\text { Grupo controle ( } n=147) \text { e grupo HU }(n=152)\end{array}$ & $\begin{array}{l}\text { A HU diminuiu as crises dolorosas em AF e reduziu custos de internação, } \\
\text { fato que compensou o uso, mas requer monitoramento clínico e } \\
\text { investigações. Limitações: não foram avaliadas qualidade de vida ou anos } \\
\text { de vida salvos. }\end{array}$ \\
\hline $\begin{array}{l}\text { Stallwort; } \\
\text { Jerrell; } \\
\text { Tripathi, } \\
2010^{(17)}\end{array}$ & $\begin{array}{l}\text { Completo. } \\
\text { Custo-benefício }\end{array}$ & Moderado & $\begin{array}{l}\text { Baseado em Coorte retrospectiva pediátrica }(n=523) \text {. } \\
\text { Razão de taxa. } \\
\text { Grupo controle }(n=348) \text { e Grupo HU }(n=175)\end{array}$ & $\begin{array}{l}\text { Necessidade de novas pesquisas observacionais de longo prazo para } \\
\text { utilização da HU em crianças. Menores episódios de dor, hospitalizações } \\
\text { e custos totais. Limitações: Dados retrospectivos, não controlados, sem } \\
\text { entrevistas e análise de abandonos. }\end{array}$ \\
\hline $\begin{array}{l}\text { Prados et al., } \\
2010^{(18)}\end{array}$ & $\begin{array}{l}\text { Completo. } \\
\text { Custo- } \\
\text { minimização }\end{array}$ & Baixo & $\begin{array}{l}\text { Baseado em coorte retrospectiva pediátrica }(n=14) \text {. } \\
\text { Teste } t \text { não pareado. } \\
\text { Grupo método de bomba }(n=10) \text { e grupo separador automático } \\
\text { de hemácias }(n=4) \text {. }\end{array}$ & $\begin{array}{l}\text { A exasanguíneotransfusão em bomba é realista, econômico e eficaz. Ideal } \\
\text { para contextos sociais com dificuldades. Limitações: Dados retrospectivos } \\
\text { de um hospital e amostra pequena. }\end{array}$ \\
\hline $\begin{array}{l}\text { Cherry et al., } \\
2012^{(19)}\end{array}$ & $\begin{array}{l}\text { Completo. } \\
\text { Custo-utilidade }\end{array}$ & Moderado & $\begin{array}{l}\text { Coorte hipotética pediátrica ( } \mathrm{n}=1000) \text {. } \\
\text { Modelo de Markov. } \\
\text { Anos de vida Ajustados pela qualidade (QALYS). } \\
\text { Grupo Doppler transcraniano (DTC) alterado com transfusão e } \\
\text { grupo DTC alterado, sem transfusão. }\end{array}$ & $\begin{array}{l}\text { A realização do DTC e identificação de risco para AVE, com transfusão } \\
\text { de sangue parece ser custo-efetivo com melhoria da condição de vida e } \\
\text { desenvolvimento. Limitações: Poucos dados clínicos referentes a transfusão } \\
\text { sanguínea na prevenção de AVE. }\end{array}$ \\
\hline $\begin{array}{l}\text { Spackman et } \\
\text { al., 2014(20) }\end{array}$ & $\begin{array}{l}\text { Completo. } \\
\text { Custo-utilidade }\end{array}$ & Moderado & $\begin{array}{l}\text { Baseado em estudo randomizado, adulto e pediátrico }(\mathrm{n}=70) \text {. } \\
\text { Simulação de Monte Carlo. } \\
\text { QALYS } \\
\text { Grupo transfusão sanguínea no pré-operatório e grupo controle. }\end{array}$ & $\begin{array}{l}\text { A transfusão de sangue no pré-operatório parece ser custo efetiva em } \\
\text { cirurgias de baixo custo e com risco moderado. Ocorreu aumento de } \\
\text { síndrome torácica aguda no grupo controle, com efeitos diretos a curto } \\
\text { prazo. Limitações: Número de pacientes, falta de QALYs em crianças. }\end{array}$ \\
\hline $\begin{array}{l}\text { Kacker et al., } \\
2014^{(21)}\end{array}$ & $\begin{array}{l}\text { Completo. } \\
\text { Custo-benefício }\end{array}$ & Moderado & $\begin{array}{l}\text { Coorte hipotética ( } \mathrm{n}=8.000) \text {. } \\
\text { Modelo de Markov. } \\
\text { Grupo correspondência prospectiva de antígenos, grupo antígeno } \\
\text { baseado na história, grupo correspondência perfeita e grupo } \\
\text { correspondência imperfeita de antígenos. }\end{array}$ & $\begin{array}{l}\text { Um teste de triagem específico para aloimunização, mesmo que imperfeito } \\
\text { poderia fornecer subsídios de benefícios clínicos em transfusão de sangue. } \\
\text { Limitações: Modelo simplificado de aloimunização, não incorporou população } \\
\text { dinâmica e representa realidades locais. }\end{array}$ \\
\hline $\begin{array}{l}\text { Kacker et al., } \\
2014^{(22)}\end{array}$ & $\begin{array}{l}\text { Completo. } \\
\text { Custo-benefício }\end{array}$ & Moderado & $\begin{array}{l}\text { Coorte hipotética ( } \mathrm{n}=8.500) \text {. } \\
\text { Modelo de Markov. } \\
\text { Grupo antígeno baseado na história e grupo correspondência } \\
\text { prospectiva com antígenos. }\end{array}$ & $\begin{array}{l}0 \text { custo seria alto para a implementação de testes de antígenos específicos } \\
\text { para aloimunização. Necessidade de pesquisas na área. Limitações: Modelo } \\
\text { simples, custos subestimados, sem custos indiretos. }\end{array}$ \\
\hline $\begin{array}{l}\text { Cunningham- } \\
\text { Myrie et al., } \\
2015^{(23)}\end{array}$ & $\begin{array}{l}\text { Completo. } \\
\text { Custo-benefício }\end{array}$ & Moderado & $\begin{array}{l}\text { Baseado em estudo de coorte retrospectiva pediátrica }(n=42) \text {. } \\
\text { Custo eficácia incremental e teste } t \text { student. } \\
\text { Grupo controle }(n=32) \text { e grupo hidroxiureia }(n=10) \text {. }\end{array}$ & $\begin{array}{l}\text { A HU é eficaz em termos de custos para prevenção de recorrências de } \\
\text { acidentes vasculares. Pode ser benéfico em ambientes com recursos } \\
\text { limitados. Limitações: Análise restrita a custos diretos, sem custos indiretos. }\end{array}$ \\
\hline $\begin{array}{l}\text { Kuznik et al., } \\
2016^{(24)}\end{array}$ & $\begin{array}{l}\text { Completo. } \\
\text { Custo- } \\
\text { efetividade }\end{array}$ & Moderado & $\begin{array}{l}\text { Coorte hipotética pediátrica ( } \mathrm{n}=228.169) \text {. } \\
\text { Modelo de Markov e anos de vida ajustados a incapacidades (DALYS). } \\
\text { Grupo controle e grupo triagem neonatal e intervenção } \\
\text { profilática. }\end{array}$ & $\begin{array}{l}\text { A triagem neonatal e a prevenção profilática seriam custo-efetivas em alguns } \\
\text { países que possuem maior incidência da doença. Necessários centros } \\
\text { especializados para o diagnóstico e tratamento. Limitações: Estimativas e custos } \\
\text { não generalizáveis. Não observou a intervenção ao longo da vida. }\end{array}$ \\
\hline
\end{tabular}


Ao analisar o nível das evidências pelo sistema GRADE, ${ }^{(14)}$ um estudo foi considerado de nível alto $(11,11 \%)$, sete de nível moderado $(77,78 \%)$ e um com nível baixo (11,11\%).

Os tratamentos dos pacientes com AF encontrados nos estudos foram a transfusão sanguínea como objetivo de cinco pesquisas $(55,56 \%)$, o tratamento medicamentoso em outras três $(33,33 \%)$ e uma com foco na triagem neonatal para AF e o tratamento $(11,11 \%)$. A população-alvo mais investigada foi a de pacientes pediátricos em seis estudos $(66,67 \%)$.

\section{Discussão}

Os estudos analisados nesta revisão demonstraram que as avaliaçóes econômicas constituem ferramentas utilizadas há pouco tempo e com importância para a prospecção dos potenciais riscos, benefícios e custos decorrentes dos tratamentos de pacientes com AF.

A realização de outras pesquisas deste nível promoverá auxílio ao desenvolvimento de diretrizes eficazes como referências para uma rede de cuidados estruturada aos pacientes com $\mathrm{AF}^{(16-18,25)}$

Todos os estudos analisados foram de avaliaçóes econômicas completas, embora apenas cinco tenham utilizado o sistema de modelagem computacional para a análise dos dados, o que evidencia tratar de uma área relativamente nova. Da amostra, sete estudos foram classificados como moderados pelo sistema GRADE, desta forma trabalhos futuros poderão modificar a confiança na estimativa de efeito referido. Estas alusōes são enfocadas por vários autores em trabalhos distintos. ${ }^{(17,20,23,25)}$

Devem ser considerados em novas pesquisas as condiçôes sociais, antecedentes e forma de acesso ao atendimento especializado para tratamento de pacientes com AF. ${ }^{(18,24)}$ Atualmente as condiçóes sociodemográficas ainda interferem no diagnóstico tardio e consequentemente no tratamento dos pacientes, fato que alerta para o fortalecimento de açôes na gestão em saúde. ${ }^{(26)}$

Tanto o diagnóstico quanto o tratamento profilático e medicamentoso de pacientes com AF ainda são considerados um problema de saúde pública em vários países, principalmente em alguns países da África Subsaariana. A melhoria da sobrevivência infantil e intervençóes devem ser repensadas, em certas áreas a expectativa de vida é estimada em 1,7 anos para crianças com AF, ou que morram antes mesmo do diagnóstico. ${ }^{(24)}$

\section{Estudos econômicos com hidroxiureia}

A partir da introduçáo do uso da HU no tratamento de crianças com AF foi percebida a diminuição no número das hospitalizaçóes, das crises dolorosas recorrentes e das complicaçóes da doença. ${ }^{(8,16,17,27)}$

Embora os estudos analisados nesta revisão não tenham avaliado a melhoria da qualidade de vida e dos anos de vida salvos, apontaram para a melhoria da condição clínica das crianças. Os custos com ambulatório, internação e serviços de emergência diminuíram após um período de 2 a 3 anos de tratamento, quando passaram de US\$12.842,00/ano/paciente iniciais para US\$ 8.839,00 no terceiro ano. ${ }^{(17)}$ Tal fato também foi apontado por outro estudo que relata uma redução total de despesas anuais de US\$ $5.210,00$ por paciente pediátrico tratado com HU. ${ }^{16}$

Destaca-se a importância da implementação de uso da HU em crianças com AF, por tratar-se de uma prática factível, viável e eficaz para prevenção de futuras complicaçóes. Entretanto, deve ser bem conduzida e acompanhada pelo serviço de saúde de forma prospectiva desde o nascimento para que não haja perdas de tratamento e complicaçóes. ${ }^{(8,27)}$

A utilização da HU também é relatada como positiva para diminuição da recorrência de AVE e do óbito de crianças com AF, descrita como custo-eficiente e com benefícios para a sociedade no que tange a manutenção da capacidade produtividade nas fases de vida. Mas sabe-se que a primeira linha de escolha é a transfusão sanguínea para prevenção de AVE recorrente em crianças. ${ }^{(23)}$ Não existem atualmente evidências fortes que garantam a utilização da HU na prevenção de AVE. ${ }^{(28)}$

Vale ressaltar que novas pesquisas são necessárias para a implementação de políticas públicas que potencializem o transplante de medula óssea em pacientes com AF, visto que a HU é considerada um tratamento paliativo e não curativo. ${ }^{(16)}$ Embora em alguns países nem mesmo o diagnóstico efetivo seja 
realizado e a mortalidade infantil venha a ser alta e demonstre as disparidades socioeconômicas. ${ }^{(24)}$

\section{Estudos econômicos com transfusão sanguínea}

O tratamento com transfusão sanguínea tradicional ou método de troca (exasanguíneotransfusão) objetiva diminuir os níveis de HbS. Este método é discutido como seguro e reduz os riscos de sobrecarga de ferro, hiperviscosidade e hipocalcemia, entre outras alteraçóes. ${ }^{(29,30)}$

A técnica automatizada de exasanguíneotransfusão com utilização de "Pump method" trata de um procedimento realista, seguro e eficaz, mais viável que os sistemas automatizados de aférese, principalmente em localidades distantes com limitaçôes geográficas, tecnológicas e de recursos financeiros. ${ }^{(18)}$ Em 2017 um estudo analisou o novo sistema automatizado de aférese para incorporação na Inglaterra, com redução de despesas de $£ 12,9$ milhões (US\$ 16,3 milhóes) por ano no tratamento de pacientes com AF que necessitam de transfusão sanguínea. ${ }^{(30)}$

Foi descrita a relação de custo-benefício do DTC para identificar o alto risco de AVE com a profilaxia por transfusóes de sangue em crianças com AF em idade acima de dois anos. ${ }^{(19)}$ Mas, devem ser analisadas crianças sem transfusóes prévias de longo prazo e com diagnóstico de risco de AVE, que provavelmente teriam o risco diminuído com o uso de transfusóes profiláticas. Entretanto, devem ser considerados os riscos e efeitos adversos da transfusão crônica, visto que não é estabelecido um limite de duração deste tipo de tratamento ou interrupção quando os exames de DTC forem normalizados. ${ }^{(23,28)}$

Houve a indicação de transfusão sanguínea no pré-operatório para pacientes com AF submetidos a cirurgia de baixo a moderado risco, a qual foi considerada pelo estudo conduzido como um procedimento custo-efetivo. ${ }^{(20)}$ Porém, não existem evidências suficientes se esta conduta consiste em uma indicação eficaz para pacientes com $\mathrm{AF}$ que serão submetidos a cirurgias, assim novas pesquisas devem ser desenvolvidas. ${ }^{(25)}$

Os artigos referentes a aloimunização decorrente de transfusôes sanguíneas em pacientes com AF salientaram pontos importantes. Visto que um teste de fenotipagem específico para aloimunização, mesmo que imperfeito poderia fornecer benefícios clínicos e ser custo-efetivo. A segurança nos serviços de transfusão é altamente priorizada, porém, requer investimento em tecnologias para garantia da qualidade quando comparada com outras áreas da saúde. ${ }^{(21,22)}$ Um longo caminho é necessário para a redução da prevalência de aloimunização de glóbulos vermelhos, visto que as pesquisas neste cenário tendem a ser custo-efetivas. ${ }^{(31)}$

\section{Conclusão}

Não foram identificadas pesquisas referentes a estudos econômicos completos realizadas no Brasil com este enfoque voltado para pacientes com AF. Os estudos enfocaram os tratamentos com HU e transfusóes de sangue, com tecnologias a serem implementadas e estruturadas nos serviços de saúde. Muito deve ser feito para análise das tecnologias vigentes, reavaliação das utilizadas e implementação de diagnóstico e tratamento precoce e contínuo, com um sistema que garanta uma rede de atenção ativa e eficiente aos pacientes com AF. Para tal, devem ser desenvolvidas pesquisas completas e robustas que considerem os recursos financeiros diretos e indiretos relativos a $\mathrm{AF}$, para contemplar o contexto dos pacientes, suas famílias e da sociedade.

\section{Agradecimentos}

Os autores agradecem ao apoio do Núcleo de Estudos Interdisciplinares em Doença Falciforme NEIDF da Universidade Federal do Mato Grosso do Sul. O presente estudo foi realizado com o apoio financeiro da Universidade Federal de Mato Grosso do Sul, da Coordenação de Aperfeiçoamento de Pessoal de Nível Superior - Brasil (CAPES) - Código de Financiamento 001 e da Fundação de Apoio ao Desenvolvimento do Ensino, Ciência e Tecnologia do Estado de Mato Grosso do Sul (FUNDECT). Obtido por meio do edital FUNDECT $\mathrm{N}^{\circ}$ 06/2017 - UNIVERSAL-MS, sob protocolo $\mathrm{n}^{\circ}$. 39136.570 .1362 .14022018 . 


\section{Referências}

1. Kato GJ, Steinberg MH, Gladwin MT. Intravascular hemolysis and the pathophysiology of sickle cell disease. J Clin Invest. 2017;127(3):75060.

2. Zhang D, Xu C, Manwani D, Frenette, PS. Neutrophils, platelets, and inflammatory pathways at the nexus of sickle cell disease pathophysiology. Blood. 2016;127(7):801-9.

3. Cançado RD, Jesus JA. Sickle cell disease in Brazil. Rev Bras Hematol Hemoter. 2007;29(3):203-6.

4. Araujo OM, Ivo ML, Ferreira Júnior MA, Pontes ER, Bispo IM, Oliveira EC. Survival and mortality in users and non-users of hydroxyurea with sickle cell disease. Rev Lat Am Enfermagem. 2015;23(1):67-73.

5. Bou-Maroun LM, Meta F, Hanba CJ, Campbell AD, Yanik GA. An analysis of inpatient pediatric sickle cell disease: Incidence, costs, and outcomes. Pediatr Blood Cancer. 2018;65(1)1-7.

6. Parise LV, Berliner N. Sickle cell disease: challenges and progress. Blood. 2016;127(7):789.

7. Chakravorty S, Williams TN. Sickle cell disease: a neglected chronic disease of increasing global health importance. Arch Dis Child. 2015;100(1):48-53.

8. Wang C, Oyeku SO, Luo Z, Boulet SL, Miller ST, Casella JF, et al. Hydroxyurea is associated with lower costs of care of young children with sickle cell anemia. Pediatrics. 2013;132(4):677-83.

9. Whittemore R, Knafl K. The integrative review: updated methodology. J Adv Nurs. 2005;52(5):546-53.

10. Stillwell S, Fineoutr-Overholt E, Melnyk B, Williamson K. Evidencebased practice, step by step: searching for the evidence. Am J Nur. 2010;110(5):41-7.

11. Fram D, Marin CM, Barbosa D. Avaliação da necessidade da revisão sistemática e a pergunta do estudo. In: Angelica Belasco MT, Taminato M, Fram D, Barbosa DA, editores. Enfermagem baseada em evidências. São Paulo: Atheneu, 2014.

12. Finetou-Oberholt E, Melnyk BM, Stillwell SB, Wiliamson KM. Evidencebased practice step by step: Critical appraisal of the evidence: part I. Am J Nur. 2010;110(7):47-52

13. Brasil. Ministério da Saúde. Secretaria de Ciência, Tecnologia e Insumos Estratégicos. Departamento de Ciência e Tecnologia. Diretrizes metodológicas: Diretriz de avaliação econômica [Internet]. Brasília (DF): Ministério da Saúde; 2014. [citado 2018 Jan 12]. Disponível em: http://bvsms.saude.gov.br/bvs/publicacoes/diretrizes_ metodologicas_diretriz_avaliacao_economica.pdf

14. Balshem H, Helfand M, Schunemann HJ, Oxman AD, Kunz R, Brozek J, et al. GRADE guidelines: 3. Rating the quality of evidence. J Clin Epidemiol. 2011;64(4):401-6.

15. Moher D, Liberati A, Tetzlaff J, Altman DG. PRISMA, G. Preferred reporting items for systematic reviews and meta-analyses: the PRISMA statement. PLoS Medicine. 2009;6(7):1 - 6.

16. Moore RD, Charache S, Terrin ML, Barton FB, Ballas SK. Costeffectiveness of hydroxyurea in sickle cell anemia. Investigators of the Multicenter Study of Hydroxyurea in Sickle Cell Anemia. Am J Hematol. 2000;64(1):26-31.
17. Stallworth JR, Jerrell JM, Tripath IV. Cost-effectiveness of hydroxyurea in reducing the frequency of pain episodes and hospitalization in pediatric sickle cell disease. Am J Hematol. 2010;85(10):795-97.

18. Prados MBV, De Jesus RG, Sein AF, Garcia MI. Efficacy, safety and costefficiency of using na alternative technique for automated exchange transfusion in pediatric patients with sickle cell disease. Bol Asoc Med P R. 2010;102(1):13-7.

19. Cherry MG, Greenhalgh J, Osipenko L, Venkatachalam M, Boland A, Dundar $Y$, et al. The clinical effectiveness and cost-effectiveness of primary stroke prevention in children with sickle cell disease: a systematic review and economic evaluation. Health Technol Assess. 2012;16(43)1-125.

20. Spackman E, Sculpher H, Howard J, Malfroy H, Llewelyn C, Choo G, et al. Cost-effectiveness analysis of preoperative transfusion in patients with sickle cell disease using evidence from the TAPS trial. Eur J Haematol. 2014;92(3):249-55.

21. Kacker S, Ness PM, Savage WJ, Frick KD, Shirey RS, King KE, et al. Economic evaluation of a hypothetical screening assay for alloimmunization risk among transfused patients with sickle cell disease. Transfusion. 2014;54(8):2034-44.

22. Kacker S, Ness PM, Savage WJ, Frick KD, Shirey RS, King KE, et al. Cost-effectiveness of prospective red blood cell antigen matching to prevent alloimmunization among sickle cell patients. Transfusion. 2014;54(1):86-97.

23. Cunningham-Myrie C, Abdulkadri A, Waugh A, Bortolusso AS, King $L G$, Knight-Madden J, et al. Hydroxyurea use in prevention of stroke recurrence in children with sickle cell disease in a developing country: A cost effectiveness analysis. Pediatr Blood Cancer. 2015;62(10):1862-4.

24. Kuznik A, Habibi AG, Munube D, Lamorde M. Newborn screening and prophylactic interventions for sickle cell disease in 47 countries in subSaharan Africa: a cost-effectiveness analysis. BMC Health Serv Res. 2016;16(304):1-12.

25. Estcourt LJ, Fortin PM, Trivella M, Hopewell S. Preoperative blood transfusions for sickle cell disease. Cochrane Database Syst Rev. 2016;(4):1-69.

26. Sarat $C N$, Ferraz MB, Ferreira Júnior MA, Corrêa Filho RA, Souza AS, Cardoso Al, et al. Prevalence of sickle cell disease in adults with delayed diagnosis. Acta Paul Enferm. 2019;32(2):202-9.

27. Thomaz R, Dulman R, Lewis A, Notarangelo B, Yang E. Prospective longitudinal follow-up of children with sickle cell disease treated with hydroxyurea since infancy. Pediatr Blood Cancer. 2019;3: e27816.

28. Fortin PM, Hopewell S, Trivella M, Wang WC, Estcourt LJ. Blood Tansfusion for preventing primary and secondary stroke in people with sickle cell disease. Cochrane Database Syst Rev. 2017;(1):1-86.

29. Swerdlow PS. Red cell exchange in sickle cell disease. Hematology Am Soc Hematol Educ Program. 2006:48-53.

30. Willits I, Cole H, Jones R, Carter K, Arber M, Jenks M, et al. Spectra Optia for automated red blood cell exchange in patients with sickle cell disease: a NICE Medical Technology Guidance. Appl Health Econ Health Policy. 2017;15(4):455-68.

31. Alkindi S, AlMahroogi S, AlHinai S, AlMarhoobi A, Al-Hosni S, Daar S, et al. Alloimmunization in patients with sickle cell disease and thalassemia: experience of a single centre in Oman. Mediterr $\mathrm{J}$ Hematol Infect Dis. 2017:9(1)1-6. 